\title{
Surprised by Values: An Introduction to Values-Based Practice and the Use of Personal Narratives in This Book
}

\author{
Bill Fulford
}

\subsection{Introduction}

Kim Woodbridge-Dodd, reflecting towards the end of this book with co-author Evette Hunkins-Hutchinson (chapter 44, 'Reflections on the impact of mental health ward staff training in race equality and values-based practice'), on their experience running a programme combining values-based practice with race equality training, expresses surprise at the difficulties they encountered:

- I did not anticipate any difficulties. In addition to my earlier experience of staff members' positive attitude to change, I knew them all well-my office was just off the ward area and I spent much of my time either on the ward or nearby. Yet as described further below, a key learning point for me was my surprise at just how difficult for staff the training in this area proved to be.

Kim was surprised by values. Values - the things that matter or are important to people - may seem obvious. But they have a disconcerting tendency to take us by surprise. Kim had many years experience working with values (she is the author of the original training manual for values-based practice, [1]) and she knew her ward staff well. Yet as she and Evette describe further in their chapter, she was much taken aback at the extent to which staff members, black and white, found their values challenged by the training.

It is the capacity of values to take us by surprise that motivates this book. Through a series of case narratives - many of them in the first person-we show how being

\section{Authors}

The editors with input from all contributors.

B. Fulford $(\bowtie)$

St Catherine's College, University of Oxford, Oxford, UK 
surprised by values (notably cultural values) allows us to open up mental health to the resources needed to support person-centred clinical care.

We describe the structure and aims of the book in more detail below. First, what exactly are values?

\subsection{Values}

What are values? Philosophers, social scientists and others have found no quick or easy answer to this question. There are indeed deep theoretical challenges here to which Part II of this book is directed. But you can get a handle on the challenges by trying the following brief exercise. ${ }^{1}$

Write down three words (or very short phrases) that mean 'values' to you. Don't think too hard about this. Just write down the first three words that come into your head. Then compare what you wrote with the triplets of words in Table 1.1.

As Table 1.1 shows, people come up with very different triplets of words in this exercise. There are overlaps ('best interests' and 'principles', for example, both appear more than once). But no three words are the same. It is very likely that if you tried this for yourself, your three words were different again.

Table 1.1 Triplets of words from the 'three words' exercise in a training session for values-based practice

\begin{tabular}{l|l}
\hline Figure 1.1_Example triplets of words in feedback from the 'three words' exercise \\
\hline Preferences & How we treat people \\
Needs & Attitudes \\
Best interests & Principles \\
\hline Respect & Non-violence \\
Personal to me & Compassion \\
Difference ... diversity & Dialogue \\
\hline Beliefs & Responsibility \\
Right/wrong to me & Accountability \\
What I am & Best interests \\
\hline Belief & What I believe \\
Principles & What makes me tick \\
Things held dear & What I won't compromise \\
\hline Subjective merits & 'Objective' core \\
Meanings & Confidentiality \\
Person-centred care & Honesty \\
\hline
\end{tabular}

\footnotetext{
${ }^{1}$ Kim Woodbridge-Dodd (co-author of chapter 'Reflections on the impact of mental health ward staff training in race equality and values-based practice') developed the three words exercise in the first training manual for values-based practice, 'Whose Values?' [1].
} 
A first surprise from this exercise is thus the diversity of meanings people attach to the very word 'values'. A second surprise is that the word 'values' carries this diversity of meanings despite being familiar in everyday usage. Given this familiarity, it is natural we should suppose that we understand what 'values' means. Well, in a sense we do (we could all write down three words). But the surprise is that we all understand something different by 'values' (we all wrote down a different three words).

\subsubsection{Values Are What Matters or Are Important to Those Concerned}

The third surprise about values shown by this exercise is that notwithstanding its diversity of meanings there is a sense in which we can still agree what 'values' means. You can see this for yourself by looking again at the words listed in Table 1.1: Do you disagree with any of them? Most people answer 'no'. Most agree with everyone else's words.

An exception (that turned out to prove the rule) was Jim Smith's sausages.

In a session on values-based surgical care for medical students, Jim Smith (not his real name), perhaps forewarned of the three words exercise, included 'sausages' in his triplet. 'Ah ah!' he said somewhat triumphantly at this point in the session, 'surely sausages have nothing to do with values!' But his colleagues quickly disabused him. 'Sausages', they pointed out, reminding him of his invariable choice of breakfast, 'have everything to do with your values!'

Jim Smith's story strongly reinforces the key learning point from this exercisethe diversity of individual meanings attached to 'values'. But this brings us back to where we started. So, just what are values? In training sessions, focusing now on values in practice, participants come to see that for clinical purposes 'values' have to be understood as including anything that matters or is important to those involved in a given situation.

The clinical relevance of this broad use of the word 'values' is shown by the story of Mrs. Jones' knee.

\subsubsection{Mrs. Jones' Knee ${ }^{2}$}

Mrs. Jones (not her real name) was referred to an orthopaedic surgeon, Mr. Patel (not his real name), with painful arthritis in one of her knees. Mr Patel confirmed the diagnosis and told Mrs Jones they could go ahead with knee replacement surgery; she would need a period of physiotherapy; but 18 months from now she would in all likelihood be pain free.

\footnotetext{
${ }^{2}$ This story has been published in a number of places. As retold here, it is adapted from one of the case studies in [2].
} 
As she got up to leave Mrs. Jones turned to Mr. Patel saying 'Thank you doctor, I'm so pleased I'll be able to garden again'. Mr. Patel asked her to tell him more. She explained that although her knee was indeed painful, what really mattered to her was that she could not bend it well enough to do her gardening. Mr. Patel then explained that while she would be pain free after the operation she would be no more mobile and possibly less so with the replacement knee joints currently available. So after further discussion they agreed to conservative management (physiotherapy and anti-inflammatories) in the first instance.

This worked well. Eighteen months later Mrs. Jones still had a painful knee but her mobility was restored and she was happily gardening again.

Mr. Patel knew from experience that pain relief was what mattered to most people with arthritic knees. This was the basis of his initial assumption about what mattered to Mrs. Jones. But had he not picked up on what actually mattered to her, the rather (in his experience) surprising value she placed on mobility (for gardening) over pain relief, Mrs. Jones would have ended up with a knee operation that although technically successful would have left her worse off (having now less mobility than before).

It is stories of this kind that explain the need for values-based practice as a partner to evidence-based practice in the delivery of contemporary person-centred clinical care.

\subsection{An Introduction to Values-Based Practice}

This section gives a brief introduction to values-based practice as a partner to evidence-based practice in clinical care.

\subsubsection{Linking Science with People}

In its partnership with evidence-based practice, values-based practice links science with people. As in the story of Mrs. Jones' knee, values-based practice links the science represented by evidence-based practice with the values of (with what matters or is important to) the individual patient involved in a given decision. The importance of this is illustrated by the following brief exercise. As with the 'three words' exercise, you may want to try this for yourself.

\subsubsection{A Clinical Decision for You}

In this exercise, you are asked to imagine yourself in the (clinically all too familiar) situation of being forced to choose between options neither of which is wholly 
satisfactory. Here, the situation is in imagination only. Even so, you may find it challenging.

You have developed early symptoms of a fatal disease. There are two possible treatments available and you can only choose one. Based on best current evidence,

- TREATMENT A-gives you a guaranteed period of remission but no cure.

- TREATMENT B-gives you a 50:50 chance of 'kill or cure'.

Now for your decision:

- How long a period of remission would you want from Treatment A to choose that treatment rather than going for the 50:50 'kill or cure' from Treatment B?

Remember the decision is about you. It is the you at your current age and in your current life situation, that is relevant, not what people in general would decide, still less what in some theoretical sense the 'right' answer would be.

Most people find this a difficult exercise-this is one of its learning points. But the main learning point is how differently people react when faced with the same choice. Everyone is offered the same options backed by the same evidence. Yet as Fig. 1.1 illustrates, people decide very differently.

The range of responses shown in Fig. 1.1 is typical. So where did you come in the range? And why did you choose the period you did? In discussion following this exercise, participants in training sessions come to see that they have made very different decisions solely because their values (the things that matter or are important to them) are very different. One person may choose, say, 20 years because they have a young family and want enough time to see them safely grown up; for another, their priority is to travel and for this a year would be enough to 'live life to the full'.

Fig. 1.1 Range of remission times required for choosing Treatment A over B

\section{Choosing treatment A over B ...}

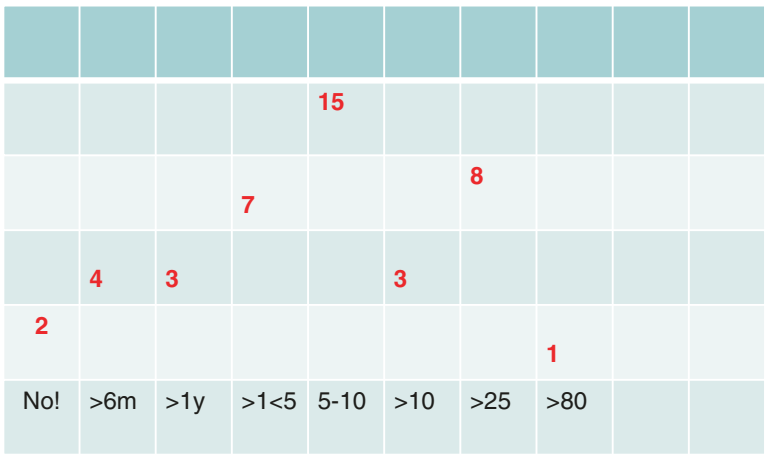




\subsubsection{Zoe Barber's Surprise}

A further surprise from this exercise for many people is just how differently people they think they know really well react from the way they expect. This was Kim Woodbridge-Dodd's surprise in the training sessions she recalled at the start of this chapter. It was the same surprise that Zoe Barber, a trainee surgeon, experienced. She recalls: ${ }^{3}$

The forced choice exercise [as above] was a 'light bulb moment' for me. I was sitting next to my partner of 6 years who is also a trainee surgeon and from a similar background to mine. We often discuss difficult clinical decisions and I feel that we share similar outlooks and ambitions. However, his 'value for choosing treatment A' (18 months) compared to mine (25 years) completely astounded me.

Once he explained his answer, I fully understood and agreed with it: his 18 months had to do with finishing his doctorate whereas my 25 years was tied up with starting a family. But at the time it was a big surprise. If I could misjudge the values of the man I share my life with so profoundly, just how wrong might I be in assuming that I know what is important to my patients? So this made me realize that unless we ask, we will never know what matters to our patients.

\subsubsection{An Outline of Values-Based Practice}

The message from the forced choice exercise can be summed up in the equation

Same evidence + Different values $=$ Different decisions

So, as Zoe Barber realised and as Mr. Patel (above) discovered from experience, we cannot just assume we know what is important to other people. This is why the first and foundational skill for values-based practice is raised awareness of the surprising diversity of individual values. As long as we assume that we know what is important to other people, values-based practice, of the kind with which this book is concerned, simply can't get started.

Getting started, however, is no more than, well, getting started. Many other skills_-communication skills, for example — are required for understanding the values in play in a given situation. And the sheer diversity of values involved brings all kinds of balancing complications into play. Hence, besides raising awareness, many further elements are required for successful implementation of values-based clinical care. These elements are shown diagrammatically in Fig. 1.2 and spelled out briefly in Table 1.2. Supported by a premise of mutual respect, ten process elements of values-based practice together support its outputs in balanced dissensual clinical decisions made within locally defined frameworks of shared values.

We return to these various elements of values-based practice in more detail in later chapters of the book (see especially the introductory chapters to each Part).

\footnotetext{
${ }^{3}$ This material is adapted from Zoe Barber's account of her experience published in [3].
} 
Fig. 1.2 A summary flow diagram of values-based practice
Premise of Mutual Respect for Differences of Values

\begin{tabular}{|l|l|l|}
\hline Ten Key Process Elements & \multicolumn{1}{|c|}{$\begin{array}{l}\text { Together these } \\
\text { support }\end{array}$} & $\begin{array}{l}\text { Balanced decisions } \\
\text { made within }\end{array}$ \\
- 2 Clinical Skills & \\
relationships & \\
- 3 Principles linking VBP & \\
and EBP & \\
- Partnership based on & \\
dissensus & & \\
\hline
\end{tabular}

Table 1.2 Brief definitions of the elements of values-based practice

\begin{tabular}{l|l}
\hline Values-based practice & Brief definition \\
\hline Premise & Mutual respect for differences of values \\
\hline Mutual respect & \\
\hline Ten process elements & \\
\hline Four clinical skills & Awareness of values and of the surprising diversity of individual values \\
\hline 1. Awareness & Knowledge retrieval and its limitations \\
\hline 2. Knowledge & $\begin{array}{l}\text { Used to explore the values in play rather than to close down on 'right } \\
\text { answers' }\end{array}$ \\
\hline 3. Reasoning & Especially for eliciting values and of conflict resolution \\
\hline 4. Communication &
\end{tabular}

\section{Two aspects of clinical relationships}

\begin{tabular}{l|l}
\hline $\begin{array}{l}\text { 5. Person-values- } \\
\text { centred care }\end{array}$ & Care centred on the actual rather than assumed values of the patient \\
\hline 6. The extended MDT & $\begin{array}{l}\text { MDT (multi-disciplinary team) role extended to include values as well } \\
\text { as knowledge and skills }\end{array}$ \\
\hline
\end{tabular}

\section{Three principles linking VBP and EBP}

\begin{tabular}{l|l}
\hline 7. Two-feet principle & $\begin{array}{l}\text { All decisions are based on the 2 feet of values and evidence, } \\
\text { including decisions about diagnosis }\end{array}$ \\
\hline $\begin{array}{l}\text { 8. Squeaky wheel } \\
\text { principle }\end{array}$ & $\begin{array}{l}\text { We notice values when they cause difficulties (like the squeaky } \\
\text { wheel) but (like the wheel that doesn't squeak) they are always there } \\
\text { and operative. (with counterpart implications for evidence) }\end{array}$ \\
\hline $\begin{array}{l}\text { 9. Science-driven } \\
\text { principle }\end{array}$ & $\begin{array}{l}\text { Advances in medical science drive the need for VBP (as well as EBP) } \\
\text { because they open up choices and with choices go values }\end{array}$
\end{tabular}

\section{Shared clinical decision-making}

\begin{tabular}{|c|c|}
\hline $\begin{array}{l}\text { 10. Shared clinical } \\
\text { decision-making based } \\
\text { on evidence and values }\end{array}$ & $\begin{array}{l}\text { Shared clinical decision-making between clinician and patient or } \\
\text { service user based on bringing together the relevant evidence with } \\
\text { the values of those concerned }\end{array}$ \\
\hline \multicolumn{2}{|l|}{ Outputs } \\
\hline $\begin{array}{l}\text { Locally defined } \\
\text { frameworks of shared } \\
\text { values }\end{array}$ & $\begin{array}{l}\text { Values shared by those concerned in a given decision-making } \\
\text { context (e.g. a GP practice) and within which balanced decisions can } \\
\text { be made on individual cases }\end{array}$ \\
\hline $\begin{array}{l}\text { Balanced dissensual } \\
\text { decisions within } \\
\text { frameworks of shared } \\
\text { values }\end{array}$ & $\begin{array}{l}\text { Balanced decisions made within the relevant locally defined } \\
\text { framework of shared values according to the circumstances } \\
\text { presented by the case in question-The framework of shared values } \\
\text { remains in play to be balanced sometimes one way and sometimes in } \\
\text { other ways according to the particular circumstances presented by } \\
\text { each case }\end{array}$ \\
\hline \multicolumn{2}{|l|}{ Values tool kit } \\
\hline \multicolumn{2}{|l|}{ Ethics } \\
\hline \multicolumn{2}{|l|}{ Law } \\
\hline Health economics & \\
\hline
\end{tabular}




\subsubsection{Limitations}

Values-based practice faces many challenges when it comes to implementation. Some of these are specific to particular circumstances. Other challenges, however, are built into the very fabric of the approach. Chief among these is what the political philosopher, Isaiah Berlin, writing in middle years of the Twentieth Century, in the shadow of National Socialism, identified as the challenge of values pluralism [4]. Our default, Berlin pointed out, when it comes to values, is monism: people want answers not options, they want to know or be told what is the right thing to do rather than having to make judgement calls. In the terms of this book, it is values monism not values pluralism that is our characteristic cultural 'value of values' as a species.

Well, values-based practice as we have described in this chapter is from top to toe pluralistic. It is all about the skills and other elements needed to support making judgement calls where complex and conflicting values are in play. Correspondingly, it has faced the challenge of pluralism when it comes to implementation (see Part VI). We return to the challenge of pluralism later in the book. As we will see cultural values although at the heart of the challenge of pluralism also provide many resources with which to respond to it (see, for example, chapter 20, 'Living at the Edge of Compromise: Balkan Pluralism as a Resource for Balanced DecisionMaking' on Balkan pluralism and chapter 21, "Thinking Too Much": A Clash of Legitimate Values in Clinical Practice Calls for an Indaba Guided by African ValuesBased Practice' on the African indaba).

Values-based practice, moreover, besides facing many and deep-rooted challenges, is no panacea. It is, indeed, just one tool among others in what may be called the 'values tool kit' of health care. Other tools in the tool kit, as Table 1.2 indicates, include ethics, law, and health economics. We give further examples in Part IV, Science, with the roles respectively of African indabas (chapter 29, 'Policy-Making Indabas to Prevent "Not Listening": An Added Recommendation from the Life Esidimeni Tragedy'), transcultural ethics (chapter 30, 'Covert Treatment in a CrossCultural Setting') and anthropology (chapter 31, 'Discouragement Towards Seeking Health Care of Older People in Rural China: The Influence of Culture and Structural Constraints'), in the values tool kit. Values-based practice adds to the tool kit a particular focus on the uniqueness of individual values and a skills-based approach to resolving the difficulties this presents in coming to balanced decisions. This is important clinically as the contributions to this book illustrate. But values-based practice, to repeat, is just one tool among many others in the values tool kit.

\subsection{Values-Based Practice and This Book}

The chapters that follow in this book are organised broadly according to the above outline of values-based practice as summarised in Table 1.2.

Part I: Exemplars, sets the scene with three worked examples (stories respectively about anorexia, abnormal body experiences and psychosis) illustrating the 
role of cultural values (positive and negative) in the causes and presentation of mental health issues.

Part II: Theory, illustrates the range of additional resources for the theory supporting values-based practice that is opened up by engaging with cultural values. Values-based practice has thus far been based on the resources mainly of the ordinary language tradition of analytic philosophy (see below, Sect. 1.4.1, 'Why Now?'). Additional resources opened up by engaging with cultural values range from aesthetics and phenomenology through qualitative social science methods to African and Asian traditions of thought and practice.

Part III: Practice, is concerned with the practical resources that cultural values bring to the development and delivery of values-based mental health services. We focus in this Part on 'person-values-centred care', on the 'extended multidisciplinary team', on 'dissensus' and its role in shared clinical decision-making and on the contributions of these and other elements of values-based practice to recoveryoriented service provision.

Part IV: Science, covers the role of cultural values in influencing the impact of science on practice. In this regard, values-based practice links science with people. Contributing chapters thus examine the three principles of values-based practice of particular importance in this and the complementary roles of other resources from the wider values tool kit.

Part V: Training, explores the additional training demands of a culturally enriched form of values-based practice and the additional resources for training that is made available by it. Contributing chapters cover the four key skills areas of values-based practice: awareness, knowledge, reasoning and communication skills.

Part VI: Reflections, deals with the RealPolitik of implementing values-based practice. The three chapters in this section report on their authors' respective experiences of implementing values-based practice 'for real' in their respective contexts. Their shared message about implementing values-based practice can be summed up in one word-difficult.

Each part of the book thus illustrates the rich resources for values-based practice opened up by extending its scope from individual to cultural values. So rich, indeed, are these resources, it is natural to ask why values-based practice has taken so long (some 20 years in fact) to fully wake up to the importance of cultural values.

\subsubsection{Why Now?}

The answer to this question brings us to yet another surprise. For the answer is that it is a result of values-based practice itself having been blind to its own inherent values! There is irony in this surprise, in that, as noted above, values-based practice starts from and places particular emphasis on the importance of raised awareness of values.

With hindsight, it is clear that there are at least two reasons for the values blindness of values-based practice, one theoretical, one practical. The theoretical reason has to do with the origins of values-based practice in ordinary language philosophy 
[5]. Interestingly, ordinary language philosophy grew out of insights into what may be called the cultural nature of language. We learn how to use words, these insights suggested, not from definitions (by looking them up in dictionaries for example) but through shared use in a social context.

When it came to applying this insight in practice, however, those concerned, consistently with the mores of their day, remained firmly individualistic in focus. J.L. Austin, for example, a founder figure in ordinary language philosophy [5], worked on the excuses made by individuals in legal court cases [6]. It is from Austin's ordinary language philosophy, applied first to the language of values [8], and then, in turn, to the language of medicine [10], that values-based practice is derived. This has proven to be a fruitful approach. Ordinary language philosophy lies behind many of the elements of values-based practice: its premise, many of its training exercises and its distinctive dissensual model of balanced decision-making [9]. All the same this was and remains an individual-centred approach.

The practical reason for the blindness of values-based practice to its own individualistic values has to do with its embedding in the equally individualist values of contemporary Western health care. The philosopher Sridhar Venkatapuram was the first to point this out [7]. Drawing on growing evidence of the importance of population-level factors as determinants of disease, he encouraged values-based practice to engage similarly at a cultural rather than merely individual level. This book thus owes its existence in part to Sridhar's acute observations.

\subsection{The Role of Personal Narratives}

In this book, each main chapter is grounded in personal narratives of one kind or another: some chapters start with conventional case histories, others are autobiographical, and still others take the form of dialogues.

\subsubsection{Personal Narratives in This Book}

In adopting this approach, we draw on deep historical and anthropological roots. Cave paintings at Lascaux in France depicting hunting scenes date from 20,000 years ago. Similar paintings recently discovered in Indonesia have pushed the origins of storytelling back still further to over 40,000 years [11]. Storytelling, indeed, as professional storyteller, Olusola Adebiyi, and co-authors, described in chapter 11, 'Madness, Mythopoetry and Medicine' has a strong track record throughout recorded human history as a resource both for teaching and for healing.

It is on this track record that we rely here. In whatever form they take, the personal narratives in this book convey, immediately and vividly, the values in play of those concerned in the stories they tell. 


\subsubsection{Personal Narratives and Evidence-Based Practice}

In grounding the book in this way on personal narratives, it might seem that we are pitting ourselves against the received medical wisdom of the day as embodied in evidence-based practice. Personal narratives, after all, come right at the bottom of the evidence hierarchy.

There are, however, dissenting voices even within evidence-based medicine. The Oxford primary care clinician, Trish Greenhalgh, for example, has called for narratives to be brought back into evidence-based medicine alongside the standardly employed quantifications [12]. Here, we extend this approach by, in effect, inverting the evidence hierarchy, turning it right-upside-down.

This is shown diagrammatically in Fig. 1.3. The idea is that just as randomised controlled trials (aggregated by robust statistical methods) are among the best ways to learn about evidence (and thus come out at the top of the evidence hierarchy), so personal narratives are among the best ways to learn about values (thus coming out at the top of the values hierarchy).

\subsubsection{Values in Evidence-Based Practice}

That learning about values through personal narratives is very far from pitting ourselves against evidence-based practice is shown by the (perhaps surprising) extent to which values are themselves intertwined with evidence in evidence-based practice.

This intertwining is evident in many ways: in the embedded values guiding science-this is touched on by professional researcher, Steven Gillard, in chapter 46, 'Beyond the Color Bar: Sharing Narratives in Order to Promote a Clearer Understanding of Mental Health Issues across Cultural and Racial Boundaries' of this book; in the early days of evidence-based practice, ${ }^{4}$ in the implementation of contemporary evidence-based practice-the UK's NICE, ${ }^{5}$ for example, includes in

Fig. 1.3 Turning the evidence hierarchy of evidence-based practice upside down in valuesbased practice

\section{Top of Hierarchy}

RCTs for evidence ... Personal narratives for values

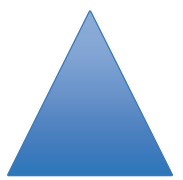

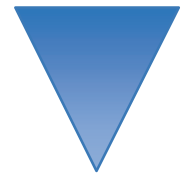

\footnotetext{
${ }^{4}$ David Sackett, in his role as first Director of Oxford's Centre for Evidence-based Medicine, defined evidence-based medicine as combining best research evidence with clinical experience and patients' values [13, p. 1].

${ }^{5}$ National Institute for Health and Care Excellence, the body responsible for producing evidencebased guidelines for the UK National Health Service.
} 
the Preface to each of its evidence-based guidelines an explicit requirement that in employing their guidelines clinicians should 'take into account the individual needs, preferences and values of their patients or service users' ${ }^{6}$ and in medical law-a recent decision from the UK's Supreme Court, the Montgomery judgement, makes consent dependent on a model of shared decision-making that brings together the clinician's knowledge of the evidence with the values of the individual patient concerned [2].

\subsubsection{Individual and Cultural Values}

In adding cultural values to the traditional focus of values-based practice on individual values, we should be careful to avoid swinging to the opposite extreme, focusing on cultural values at the expense of the individual. When it comes to values, as one of us has put it elsewhere [14], 'everyone is an $n$ of 1 '.

But here, too, personal narratives of the kind privileged in this book have a role to play. For in exploring cultural values through personal narratives, the person or persons with their individual values at the heart of each story, and their often surprising and uniquely individual ways of reacting within their respective cultures, remain very much at the front of our minds.

\subsection{Conclusions}

This chapter has provided an introduction to the book.

- Section 2 described the key features of values relevant to understanding their role in health care-in this context (and correspondingly in values-based practice), values include anything that matters or is important to those concerned in a given situation.

- Section 3 gave an overview of the framework elements of values-based practice. As summarised in Table 1.2, these elements cover, skills, service model, links between values and evidence, and shared clinical decision-making based on dissensual balancing within frameworks of shared values.

- Section 4 outlined the structure of the book indicating how this reflects the framework elements of values-based practice while extending its scope from individual to cultural values.

- Section 5 explained the prominence given to personal narratives in this book: personal narratives, we suggested, offer a powerful way of exploring values much as randomised controlled trials offer a powerful way of exploring evidence.

\footnotetext{
${ }^{6}$ See for example: National Institute for Health and Care Excellence (2015/2017) Suspected cancer: recognition and referral: NICE guideline NG12 (published date: June 2015. Last updated: July 2017) at: https://www.nice.org.uk/guidance/ng12 [and scroll down the page to the statement 'Your Responsibility'].
} 
A theme running through this chapter has been the many surprises thrown by values: Kim Woodbridge-Dodd's surprise at the values revealed by mental health staff in a training exercise; Mr. Patel's surprise at Mrs. Jones' preference for mobility over pain relief in the treatment of her arthritic knee; Zoe Barber's surprise at her partner's values revealed by the 'forced choice' exercise; our own surprise that values-based practice had remained for so long blind to the influence of its own innate values of individualism; and surprises all round at the elevation of personal narratives from the bottom of the evidence hierarchy to the top of the values hierarchy.

And values have still one more surprise to spring, rather a pleasant surprise in fact, a surprise we will call the 'mental health first' surprise. But we will have more to say about that at the end of the book in our concluding chapter.

\subsection{Guide to Further Information}

For more on values-based practice including developments in values-based surgical care, please see the website for the Collaborating Centre for Values-based Practice in Oxford at: valuesbasedpractice.org.

The website includes a special section of its bespoke 'wikiVBP library' dedicated to the links and other materials indicated in the Guides to Further Information included in the chapters of this book.

\section{References}

1. Woodbridge K, Fulford KWM. 'Whose values?' A workbook for values-based practice in mental health care. London: The Sainsbury Centre for Mental Health; 2004.

2. Herring J, Fulford KWM, Dunn D, Handa A. Elbow room for best practice? Montgomery, patients' values, and balanced decision-making in person-centred care. Med Law Rev. 2017;25(4):582-603. https://doi.org/10.1093/medlaw/fwx029. https://academic.oup.com/ medlaw/advance-articles.

3. Handa IA, Fulford-Smith L, Barber ZE, Dobbs TD, Fulford KWM, Peile E. The importance of seeing things from someone else's point of view. BMJ Careers on-line Journal (Published in hard copy as 'Learning to talk about values'). 2016. http://careers.bmj.com/careers/advice/ The_importance_of_seeing_things_from_someone_else's_point_of_view.

4. Berlin I. Two concepts of liberty. Oxford: Clarendon Press; 1958.

5. Fulford KWM, van Staden W. Values-based practice: topsy-turvy take home messages from ordinary language philosophy (and a few next steps). Chapter 26. In: Fulford KWM, Davies M, Gipps R, Graham G, Sadler J, Stanghellini G, Thornton T, editors. The Oxford handbook of philosophy and psychiatry. Oxford: Oxford University Press; 2013. p. $385-412$.

6. Austin JL. A plea for excuses. Proc Aristotelian Soc. 1956-1957;57:1-30. Reprinted in White AR, editor. The philosophy of action. Oxford: Oxford University Press; 1968. p. 19-42.

7. Hare RM. The language of morals. Oxford: Oxford University Press; 1952.

8. Fulford KWM. Moral theory and medical practice. Cambridge: Cambridge University Press; 1989, reprinted 1995 and 1999. 
9. Fulford KWM. Living with uncertainty: a first-person-plural response to eleven commentaries on values-based practice. Chapter 13. In: Loughlin M, editor. Debates in values-based practice: arguments for and against. Cambridge: Cambridge University Press; 2014.

10. Venkatapuram S. Values-based practice and global health. Chapter 11. In: Loughlin M, editor. Debates in values-based practice: arguments for and against. Cambridge: Cambridge University Press; 2014.

11. New Scientist report (14 Dec 2019, p. 19) The earliest story tellers, citing. Nature. https://doi. org/10.1038/s41586-019-1806-y.

12. Greenhalgh T, Hurwitz B. Narrative based medicine: dialogue and discourse in clinical practice. London: BMJ Books; 1998.

13. Sackett DL, Straus SE, Scott Richardson W, Rosenberg W, Haynes RB. Evidence-based medicine: how to practice and teach EBM. 2nd ed. Edinburgh: Churchill Livingstone; 2000.

14. Fulford KWM, Peile E, Carroll H. A smoking enigma: getting and not getting the knowledge. Ch 6. In: Fulford KWM, Peile E, Carroll H, editors. Essential values-based practice: clinical stories linking science with people. Cambridge: Cambridge University Press; 2012. p. 65-82.

Open Access This chapter is licensed under the terms of the Creative Commons Attribution 4.0 International License (http://creativecommons.org/licenses/by/4.0/), which permits use, sharing, adaptation, distribution and reproduction in any medium or format, as long as you give appropriate credit to the original author(s) and the source, provide a link to the Creative Commons license and indicate if changes were made.

The images or other third party material in this chapter are included in the chapter's Creative Commons license, unless indicated otherwise in a credit line to the material. If material is not included in the chapter's Creative Commons license and your intended use is not permitted by statutory regulation or exceeds the permitted use, you will need to obtain permission directly from the copyright holder.

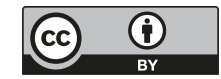

